
internationales

vol. 36 - $n^{\circ} 4 \mid 2020$

La citoyenneté au temps de l'« intégration civique » : regards croisés France/Canada

\title{
Fer Yannick et Malogne-Fer Gwendoline, Le Protestantisme à Paris. Diversité et recompositions contemporaines
}

Ralph Schor

\section{(2) OpenEdition}

\section{Journals}

Édition électronique

URL : https://journals.openedition.org/remi/17689

DOI : $10.4000 /$ remi. 17689

ISSN : $1777-5418$

Éditeur

Université de Poitiers

Édition imprimée

Date de publication : 31 décembre 2020

Pagination : 199-200

ISBN : 979-10-90426-68-9

ISSN : 0765-0752

\section{Référence électronique}

Ralph Schor, «Fer Yannick et Malogne-Fer Gwendoline, Le Protestantisme à Paris. Diversité et

recompositions contemporaines ", Revue européenne des migrations internationales [En ligne], vol. 36 -

n4 | 2020, mis en ligne le 31 décembre 2020, consulté le 15 avril 2022. URL : http://

journals.openedition.org/remi/17689; DOI : https://doi.org/10.4000/remi.17689

Ce document a été généré automatiquement le 15 avril 2022.

(c) Université de Poitiers 


\title{
Fer Yannick et Malogne-Fer Gwendoline, Le Protestantisme à Paris. Diversité et recompositions contemporaines
}

\author{
Ralph Schor
}

\section{RÉFÉRENCE}

Fer Yannick et Malogne-Fer Gwendoline (Dirs.) (2017) Le Protestantisme à Paris. Diversité et recompositions contemporaines. - Genève : Labor et Fides. - 418 p., ISBN :

978-2-8309-1599-0

Une équipe d'universitaires, principalement sociologues, anthropologues et historiens, brosse un portrait précis et nuancé du protestantisme parisien actuel.

Le livre souligne d'abord la juxtaposition de plusieurs Églises protestantes qu'on peut schématiquement regrouper en deux familles : le tronc historique qui constitue l'Église protestante unie de France et les évangéliques, souvent d'origine immigrée. Ces derniers deviennent parfois majoritaires, comme à Melun, et l'on peut alors observer une africanisation des Églises, d'autant que des pasteurs étrangers se trouvent parfois à la tête de certaines paroisses. Cette situation peut être comprise comme une ouverture à l'altérité et l'amorce d'un processus d'intégration dans la société du pays d'accueil : près d'un tiers des conseillers presbytéraux ont passé leur jeunesse hors de la France métropolitaine. La Fédération protestante essaie de sensibiliser les fidèles à la diversité culturelle et les invite à bâtir des ponts entre les Églises. Mais l'équilibre ne s'établit pas facilement. La Fédération est consciente de sa responsabilité consistant à représenter tout le protestantisme et, en même temps, elle ne veut pas être confondue avec les courants évangéliques issus de l'immigration, réputés moins intellectuels et privilégiant des pratiques très démonstratives, bruyantes, charismatiques. Certains 
fidèles traditionnels, mal à l'aise dans une paroisse animée par les évangéliques étrangers, partent à la recherche d'un autre lieu de culte plus conforme à leurs attentes. Dans certaines paroisses, les étrangers, accueillis pendant un certain temps, sont priés de partir, car ils se révèlent trop différents ou trop nombreux. Ce fut le cas des Africains francophones dans le Temple du Marais. Chez les anglicans, les Tamouls du Sri Lanka restent en marge.

3 Les Églises évangéliques étrangères, qui réunissent des effectifs de niveau social modeste, résident surtout en banlieue, jouent un rôle social et religieux important en dispensant à leurs fidèles des aides diverses et des conseils, en tenant un rôle de médiatrices avec la France, en maintenant des liens avec le pays d'origine, en valorisant la fonction des membres de l'Église invités à construire un avenir idéalisé et à évangéliser les Français. La cathédrale américaine de Paris estime avoir aussi un devoir d'accueil auprès des militants LGBT, principalement francophones, qui la rejoignent. Les évangéliques arabes, égyptiens, libanais, maghrébins souhaitent convertir les musulmans en leur montrant qu'il existe une communauté culturelle entre le christianisme et l'islam, en rappelant que Jésus était un sémite. Certains étrangers, comme les Chinois Wenzhou, s'attachent à organiser et à institutionnaliser leurs Églises. Les protestants nouveaux venus en France, se démarquant de leurs frères luthéro-réformés ancrés dans une tradition de discrétion, essaient d'acquérir une plus grande visibilité sociale, ce qui peut engendrer une volonté de représentativité dont, jusqu'alors, le tronc luthérien détenait le monopole.

4 Ainsi le livre met bien en évidence la diversité du protestantisme, plus forte que jamais, diversité sociale, culturelle, théologique, générationnelle, territoriale. Les processus d'intégration ou de différenciation sont bien décrits, de même que les liens entre les faits religieux et les espaces urbains. La complexité des identités et de leurs évolutions inspire des passages passionnants. L'ouvrage, d'une évidente richesse, apporte une précieuse contribution à la connaissance du protestantisme contemporain.

\section{AUTEURS}

\section{RALPH SCHOR}

Historien, Professeur émérite, Université Côte-d'Azur/CMMC 